\title{
VIRGIN RIVER SPINEDACE HABITAT PREFERENCE STUDY
}

\author{
James E. Deacon \\ Anga Rebane \\ Department of Biological Sciences \\ University of Nevada \\ Las Vegas
}

Thus far in the study, 4 species of endemic fishes and 2 introduced trout species have been collected, measured for total length, and in some cases, weighed, and then released. Sampling has been accomplished by electroshocking on $6,7,8$, and 9 July, 1987, at 4 sites on the East and North Forks of the Virgin River, as well as 1 site on the Santa Clara River, and 1 site on Moody Wash near Mogatsu Creek, a tributary of the Santa Clara River. Seining, measuring, and releasing was done on 3, 4, and 20 September, 4 and 10 October, and on 9 and 10 January, 1988, at five sites on the East and North Forks of the Virgin River. Electroshocking was used on 9 January, 1988 at one of the North Fork sites, utilizing a backpack electroshocker unit borrowed from Donna Withers, of the Nevada Department of Wildlife. On 24, 29, and 30 August, fish were surveyed by seining or dip netting at Lytle Ranch, on Beaver Dam Wash, a tributary of the Virgin River, for purposes of determining favorable habitat conditions under a different regime. Electroshocking was determined to be limited in use in the Virgin River system, due to the frequent turbidity of the water, and the depth of the pools. In winter we have not collected substantial numbers of any species, with either electroshocking or seining techniques. It is possible that the fish are located in places unaccessible to our sampling techniques, or possibly they have undertaken significant migration to other locations, most likely towards the warmer waters of lower elevations. Mass mortality can be ruled out due to the fact that all fish species have been observed to reappear in early spring. We need to revise our sampling techniques, and are working on a variety of different procedures to be able to collect fish in winter, or find out where they live. The limitations of the winter habitat may prove to be an important factor in the continued success of the spinedace in the Virgin River in zion. The borrowed electroshocking equipment seems marginally successful in sampling fishes in the highly conductive water of the Virgin. A more powerful unit needs to be procured. When the water is clear, shocking works well because the fish can be visualized and netted while immobilized by the shocker, but the frequent turbidity of the water would make any fish not surfacing impossible to see and catch, even though it was immobilized.

These conditions of visibility enhance the results of seining efforts, as the fish are unable to see the researchers approaching, and therefore are less likely to orient away from the seine and escape. Seining also has its limitations under winter conditions, as the fish are not in 
their usual shallow habitats, and the water temperature precludes seining in depths greater than those for which access is allowable by waders. It is assumed that precisely those depths are the favored habitat for the fish during the coldest months, when temperatures force them into a torpid state of low metabolic activity. A technique using a rubber raft to float the electroshocking team above deep holes in the river might prove the most successful in rousing the fish and obtaining a true indication of population numbers and distribution at this time.

Coordination with Zion National Park has been aided by Larry Hays, Resource Specialist. Several meetings have been held with members of the Water Rights Branch of the Water Resources Division of the National Park Service to coordinate research efforts and sampling stations, and to share results of the various efforts. The most recent meeting was held on December 8, 1987. Those involved included Terry Boyle who is investigating macroinvertebrates and periphyton in the river, Alice Johns and Gary Smillie, who together with Owen Williams, are working on a physical habitat model of the river at different flow regimes. Also present was Thom Hardy of Utah State University and Bio West, Inc., who is advising us on computer matters and supplying the Instream Flow Incremental Methodology programs to develop the habitat preference curves. This coordination will result in a much more complete picture of the physical and biological parameters involved with the Virgin River in and near Zion National Park.

The Zenith personal computer is operational, and field data have been entered into the physical habitat simulation model program. For all fish collections, and null sets, where no fish were collected due to winter temperatures or other unfavorable habitat conditions, the computer has accepted habitat parameters of depth, distance from shore, substrate, cover, current velocity, and air and water temperatures. This will be correlated with spinedace utilization, perhaps as well as utilization by the other species of fish endemic to the river system, since the data are being collected on them at the same time as the Spinedace data. These data, when merged with the Physical Habitat Simulation Model program, will yield a preliminary habitat preference curve, and this in turn will be utilized to determine any variations in field collection procedures throughout the 1988 collecting season. 